\section{Horse dope-dispute rages on}

\section{London}

THE horse-doping dispute between the Aga Khan and the Jockey Club, which regulates horseracing in Britain, has thrown a pall of gloom over the British horseracing community, chiefly because of the injured owner's decision to move his collection of 90 racehorses elsewhere. But the dispute may be the best thing yet to have happened to equine metabolic studies.

The dispute centres on the Aga Khan's horse Aliysa, which came first in a race called the Oaks at Epsom, southwest of London, on 10 June 1989. Random testing at the Horseracing Forensic Laboratory (HFL) at Newmarket found in the horse's urine detectable amounts of 3-hydroxycamphor, a metabolite of camphor which is itself believed to be a stimulant of the central nervous and respiratory systems. Aliysa was disqualified by the Jockey Club at the end of last month.

In the intervening eighteen months, both the reliability of the Jockey Club's screening methods and its interpretation of its data have been seriously criticized, mostly on the basis of investigations at the University of California at Davis and at the University of Quebec at Montreal, all commissioned by the Aga Khan.

The original complaint against Aliysa, lodged 10 days after the race, was based on a gas-chromatography mass-spectrometry assay used at HFL for screening urine and blood samples. It seems not to be disputed that detectable quantities of 3-hydroxycamphor were found in the urine, but no quantitative estimate was made. The detection limit is believed to have been about 125 nanograms per millilitre.

Professor Robert Massé, deputy director of the Canadian Center for Doping Control at Montreal (which is mostly concerned with human athletes) says that screening assays alone are insufficient to support a positive dope finding, and that they should always be followed by assays designed for the suspect substances.

Massé also says that the analyses at HFL were not as reproducible as they should have been. Mr Neville Dunnett, director of the laboratory, explains that by the need for haste in meeting a deadline for the adjourned Jockey Club enquiry.

But the more interesting disagreement centres on the origin of 3-hydroxycamphor in horses' urine. Gary Henderson from Davis says that feeding trials with horses there have shown that the metabolite can arise from naturally occurring substances other than camphor, including the closely related monterpene borneol and the wood constituents $\alpha$ and $\beta$ pinene. Massé says

that horses bedded on wood shavings at the stables from which Aliysa raced have been found to have the metabolite in their urine.

Part of the panel's case against the Jockey Club's decision is that, in circumstances in which the metabolite can arise from materials in the horses' environment, there should at least be a threshold concentration to determine when it has arisen unnaturally. Such a limit now exists for the finding of salicylic acid in a horse's urine

Dunnett says that that the Jockey Club's rules are deliberately "black and white" to protect the "integrity of British racing". The rule is that a horse with a prohibited substance in its blood should not be racing even if the material got there by some natural route. "Occasionally, it may be a harsh rule", he says.

John Maddox

INDUSTRIAL/ACADEMIC COLLABORATION -

\title{
Rule change revives LINK
} London

THE UK Department of Trade and Industry (DTI) will no longer discourage applications to the government's LINK research programme involving only one company. The change, announced by industry minister Lord Hesketh, is designed to increase participation by small companies, which have been discouraged by the perceived domination of projects by large companies.

LINK was set up in 1988 to bring academic and industrial researchers together in collaborative projects, but has been slow to get off the ground. Less than $£ 40$ million of the $£ 210$ million the government had hoped to spend by 1992-93 has so far been earmarked for specific projects, and the strict rules that govern the programme have been blamed.

Other changes are expected to follow. A team of independent consultants is now looking for ways to increase the uptake of LINK money, and expects to report to LINK's steering committee before Christmas.

The programme's critics argue that the selection of LINK projects could be streamlined, and that the government should contribute more than the 50 per cent it currently gives towards the cost of each project. Where a large proportion of a LINK project is university based, the 50 per cent limit means that industrial partners have to bear most of their own costs. Other similar initiatives, such as the European Communities' ESPRIT information technology programme, provide a powerful incentive for companies to take part by paying half of their research costs.

Peter Aldhous 